\title{
Historiografía académica e historia escolar. Los libros de texto de historia entre dos centenarios*
}

\author{
Academic historiography and school history teaching. History textbooks \\ between two centennials
}

\author{
Mariana Lewkowicz \\ mariana.lewkowicz@gmail.com \\ Docente - Investigadora \\ Instituto de Investigaciones en Ciencias de la Educación, Facultad de Filosofía y Letras, \\ Universidad de Buenos Aires \\ UNIPE/INFOD \\ Galicia 128, CABA, 1414 \\ Argentina

\section{Martha Rodríguez} \\ mrod@fibertel.com.ar \\ Docente - Investigadora \\ Programa de Investigaciones en Historiografía Argentina, Instituto de Historia Argentina y \\ Americana "Dr. E. Ravignani", Universidad de Buenos Aires/CONICET \\ Ladislao Martinez, 238 PB \\ Martínez, Prov. de Buenos Aires, 1640 \\ Argentina
}

\section{Resumen}

El uso escolar que se hace de la historia, los contenidos de historia que se enseñan en los distintos niveles del sistema educativo mantiene con la historiografía académica una compleja y profunda relación. Las representaciones del pasado que elabora la historia escolar son irreductibles al saber institucionalizado producido por la historiografía. En este artículo nos proponemos analizar en los libros de texto publicados en la década anterior y posterior a los dos centenarios de la Revolución de Mayo (1910-2010), la forma en que es presentado el proceso revolucionario iniciado en 1810 y la relación que guardan esas imágenes con las interpretaciones que para esos procesos había estabilizado en cada uno de esos momentos la historiografía académica. Para ello exploraremos las formas como fue entendida la historia, su función en el sistema educativo, las relaciones entre esos relatos y los construidos por la historiografía académica.

\section{Palabras-clave}

Historiografía argentina; Cultura histórica; Historia.

\begin{abstract}
The school use made of history, the contents of history taught in the school maintain with academic historiography a complex and deep relationship but representations of the past that made school history are irreductible to institutionalized knowlege by historiography. In this article we analyze in textbooks published in the anterior and posterior decades to the two centennials of the May Revolution (1910-2010), the way the revolutionary process commenced in 1810 is presented and how it relates to these images with the interpretations academic historiography had stabilized in each one of the moments. To explore the ways it was understood history, its role in the educational system, the relationships between those stories and those built by academic historiography.
\end{abstract}

\section{Keywords}

Argentina historiography; Historical culture; History.

Recibido el: 26/8/2015

Aceptado el: 16/11/2015

\footnotetext{
* En los inicios de esta investigación, algunos resultados preliminares fueron presentados en las XVI Jornadas Argentinas de Historia de la Educación realizadas en la Universidad Nacional de Entre Ríos en 2010. Allí nos beneficiamos con los comentarios de las coordinadoras de la mesa, Carolina Kaufmann y Delfina Doval, y del resto de los participantes.
} 
Cuando en 1986 Habermas, en el contexto de la Historikerstreit alemana, introducía el concepto de uso público de la historia, iluminaba sin saberlo un campo de exploración más que interesante para los historiadores de la historiografía. Aunque su intervención en ese debate tenía por objeto saldar cuentas con el revisionismo histórico conservador alemán en torno a la interpretación de la identidad histórica y política de la República Federal Alemana -y en particular su vínculo con el nazismo-, al calor de ese debate acuñó una expresión destinada a tener un éxito considerable en las décadas siguientes. Con ella, Ilamaba la atención sobre las diferencias y las distancias existentes entre el tratamiento propiamente historiográfico de la historia por parte de los especialistas y su utilización en la esfera pública. ${ }^{1}$

Esta distinción ampliaba considerablemente para la historiografía el repertorio de problemas a indagar, adicionando a la atención centrada en los procesos de producción y circulación del conocimiento histórico dentro del mundo académico - que demandaba estudiar obras históricas, historiadores, publicaciones e instituciones productoras de discursos históricos - aquellos derivados de la circulación (también de la creación) de relatos históricos entre diversos grupos sociales, los modos de apropiación y recepción de imágenes, representaciones e interpretaciones. Al mismo tiempo, ponía luz sobre las diferentes formas de gestión del conocimiento histórico y las relaciones constantemente redefinidas entre un saber académico y su transmisión a la sociedad (CARRERA ARES; FORCADELL ALVAREZ 2003).

También desde el mundo alemán y más o menos para la misma época, J. Rüsen ponía en circulación una noción para reflexionar en torno de estas cuestiones. El concepto de cultura histórica era una fórmula que intentaba dar cuenta de las formas de pensar y comprender la relación que un grupo humano mantiene con su pasado (RÜSEN 1994). Se trataba de analizar la construcción del significado asignado al pasado mediado por la conciencia histórica más allá del ámbito de la historiografía, la conciencia que el presente tiene del pasado, inseparable de la tensión siempre presente entre espacio de experiencia y horizonte de expectativa formulada en la ya clásica acepción koselekiana.

Al no restringir la cultura histórica a la Historia (en tanto campo de conocimiento) sino ampliarla al accionar de todos aquellos mediadores entre el pasado y el presente en el espacio social, político y cultural, estas reflexiones operaron como trasfondo hermenéutico para potenciar un campo de estudio no circunscripto al análisis de la literatura histórica académica, y atento a las complejas formas de la elaboración social de la experiencia histórica y su materialización, los agentes sociales que la crean, los medios por los que se difunde, las representaciones que divulgan. Esta indagación sobre las relaciones que los grupos humanos mantienen con su pasado condujo a la exploración de otros objetos que funcionaron y funcionan como mediadores y generadores de imaginarios sociales con sus correlativas derivas

\footnotetext{
${ }_{1}$ De la rápida adopción del concepto por parte de la historiografía da cuenta la multiplicación de obras que lo toman como eje de sus análisis (Cf.: GALLERANO 1995; HARTOG; REVEL 2001; CARRERA ARES; FORCADELL 2003; entre otros).
} 
historiográficas, pedagógicas, culturales, sociales, y políticas, como el patrimonio histórico, la divulgación histórica, los medios de comunicación, la enseñanza escolar, los materiales didácticos.

Los estudios sobre estos dos últimos -la enseñanza escolar y los materiales didácticos- desplegados desde la historiografía en las últimas dos décadas son un ejemplo interesante de las aproximaciones a las que aludíamos. A diferencia del histórico interés de la didáctica y la pedagogía por los libros de texto y otros materiales didácticos, su incorporación como fuente o como objeto de estudio en el ámbito de las ciencias sociales fue bastante más reciente (RODRÍGUEZ 2015). En este "descubrimiento" empezaron a ser pensados no sólo como el producto de consideraciones de tipo didáctico y pedagógico, sino también como el resultado de la convergencia de otras lógicas como las disciplinares, las estatales, las de la política, las demandas sociales, el mercado, las empresas editoriales. Y mutatis mutandis como objetos valiosos para indagar ciertas formas de intervención sobre las interpretaciones del mundo -y de sus propios pasados- que a lo largo del tiempo construyeron las sociedades.

En la Argentina, por ejemplo, la indagación sobre los materiales didácticos en general y sobre los libros de texto en particular por parte de la historiografía y de la historia de la educación, ha cobrado relevancia en las últimas décadas, dando lugar a una profusa bibliografía y a la constitución de equipos de investigación y programas en las universidades dedicados al estudio de estos temas (OSSENBACH; SAMOZA 2001; RODRIGUEZ; DOBAÑO 2001; KAUFMANN 2015). En general estas investigaciones se centraron en el estudio de textos escolares producidos en tres períodos particulares de la historia argentina. Uno de los momentos privilegiados fue la segunda mitad del siglo XIX y las primeras décadas del XX, momento clave en el proceso de constitución de un estado y de un sistema educativo nacional pensado con la doble función de educar al ciudadano y argentinizar a la heterogénea población del país. Para cumplir con estos propósitos se diseñaron contenidos, se formaron docentes y se produjeron manuales escolares, que se convirtieron en fuentes privilegiadas para analizar los mecanismos de construcción y transmisión de una identidad nacional (ROMERO 2004; CUCUZZA 2007; GVIRTZ; BARREIRO 1998; HUARTE; VAN DER HORST 2002; MARISTANY 2005; BRASLAVSKY 1992; DEVOTO 1993). ${ }^{2}$ El segundo momento corresponde al primer peronismo; los libros de texto producidos en ese período fueron analizados a la luz de los intentos de construir, consolidar y difundir una doctrina nacional, apoyada en una particular imagen de la sociedad, del pasado y del movimiento peronista (PLOTKIN 1994; AMÉZOLA 1996; CUCUZZA; SOMOZA 2001; CUCUZZA; PENEAU 2002; COLOTTA; SOMOZA 2001; CORA; RODRIGUEZ 2015). El tercer período estudiado fueron

\footnotetext{
${ }^{2}$ No es necesario ahondar aquí en el hecho de que la construcción de una identidad nacional no es reductible a la transmisión de contenidos desde el sistema educativo. Si bien la historia escolar es un instrumento privilegiado para moldear la cultura histórica de una sociedad; el conjunto de ideas que circulan en ella y conforman su imaginario es, como señalamos, mucho más complejo y contradictorio que, por ejemplo, los contenidos de los libros de texto que se utilizan en la educación formal.
} 
las últimas décadas, en los que se produjo una convergencia particularmente fecunda con la historia reciente. Por un lado, el interés por el análisis de las características que asumió el proyecto educativo y cultural llevado adelante por la dictadura militar y la dinámica que adquirió en este contexto el sistema educativo, motivó no pocas investigaciones centradas en los libros de texto. Por otro lado, las transformaciones en la estructura académica, la organización institucional y la estructura curricular operada en el sistema educativo desde principios de la década del ' 90 , sumadas a la renovación de la historiografía, convergieron para impulsar una extendida y profunda transformación en los libros de texto. Los nuevos diseños, contenidos, marcos teóricos y didácticos fueron objeto de análisis de varios artículos y libros en los últimos años (AMÉZOLA 1997, 2008; BRASLAVSKY 1991; EGGES BRASS 2006; KAUFFMAN 2006, 2009, 2015; KAUFFMAN; DOVAL 1997; RODRÍGUEZ; DOBAÑO 2001; DOBAÑO; RODRÍGUEZ 2009; RODRIGÍGUEZ 2009).

En general, las investigaciones centradas en el primero de los períodos mencionados han privilegiado el trabajo con libros para la escuela primaria. Este interés no es casual, ciertamente era el nivel primario el que, tanto para las elites dirigentes como para el mundo intelectual, actuaba como la principal correa de transmisión de los sentimientos, imágenes y valores destinados a la construcción de una memoria pública en la que todos los habitantes se vieran reflejados. Y fueron estos temas los que centralmente se abordaron en las investigaciones. Menos explorados están los libros destinados al nivel medio y los abordajes que privilegian el análisis del relato histórico y su sentido, sus particularidades y sus relaciones con aquellos construidos por la historiografía académica.

En este trabajo nos centraremos en el análisis de libros de historia producidos para el nivel medio en el marco temporal que va desde la década anterior hasta la posterior de dos momentos: el del Centenario y el del Bicentenario de la Revolución de Mayo, producidos en 1910 y 2010 respectivamente. En ellos exploraremos las formas como fue entendida la historia, su función en el sistema educativo, las relaciones entre esos relatos y los construidos por la historiografía académica. ${ }^{3}$ Focalizaremos estas cuestiones en las interpretaciones que los autores en uno y otro contexto hacen del momento en que comienza la ruptura del vínculo colonial y la lectura que realizan de Mayo de 1810. Aún a riesgo de opacar matices, en esta indagación priorizaremos el análisis de conjunto de los textos de cada período por sobre las comparaciones al interior de cada etapa; los elementos comunes y aproximaciones generales por sobre las diferencias y el estudio de cada texto en particular. La heterogeneidad de la muestra, en la que se han incluido libros para distintos años dentro de cada nivel tiene que ver con nuestro interés de

\footnotetext{
${ }^{3}$ El tema de las relaciones entre la historia escolar y la disciplina en el ámbito académico es complejo y suscita intensos debates que no seria pertinente detallar aquí. Es importante tener en cuenta la perspectiva de la historia como disciplina escolar que sugiere Cuesta Fernández: "Un arbitrario cultural creado históricamente en razón de la práctica de diversos agentes sociales entre los que desempeña un indudable protagonismo los profesores y los alumnos, las profesoras y las alumnas, que con su acción han creado y transformado a lo largo del tiempo una tradición social" (CUESTA FERNÁNDEZ 1997). Así, consideramos con Chervel que la historia escolar posee un grado de autonomía con respecto a las ciencias de referencia y que debemos concebir los contenidos de enseñanza como entidades sui generis, más complejos que meras adaptaciones de los conocimientos científicos (CHERVEL 1991).
} 
presentar un panorama amplio de los libros para el nivel medio, susceptible de ser profundizado y ampliado en investigaciones posteriores.

Para ejemplificar el análisis hemos incluido referencias a los siguientes textos: Para primer Centenario, Errotaberea (1910), García Merou (1922) La primera edición es de 1907 -, De Vedia (1913), Torre, Carbia, Ravignani; Molinari, (1917); Levene (1912). Para el momento del bicentenario Burucua (2006) Alonso., Blanco y otros (2003) Chiaramonte (2006), Rizzi y otros (2009), Buonome, y otros (2010) y Carrozza y otros (2010).

\section{El Centenario: libros de texto, historia y educación}

Los años en torno al Centenario estuvieron surcados de reflexiones en las que se entrecruzaban la cuestión social, la cuestión nacional y el balance del camino recorrido desde la ya secular Revolución de Mayo. El sistema educativo ocupaba un lugar no menor en todas estas preocupaciones, aunque algunas de ellas desplegaran ya luces y sombras sobre sus resultados. Desde sus albores en la segunda mitad del siglo XIX las elites estatales proyectaron sobre la educación un objetivo civilizador y de integración social, formar a los ciudadanos de la patria, convertir a los individuos en parte de una comunidad de alcance nacional. A comienzos del siglo XX, aquella convicción comenzaba a resquebrajarse por lo que, tal como sostenía Ricardo Rojas en La restauración nacionalista era necesario reforzar una educación patriótica e ilustrada (ROJAS 1971). En este proyecto la historia, sus cultores, sus obras y sus instituciones desempeñaban el papel estratégico de constructores de un relato nacional en el que todos los habitantes se "reconocieran", fundamento de una identidad nacional homogénea capaz de conjurar el conflicto y la desintegración social.

Simultáneamente, - y en gran medida influido por las demandas estatales y el apoyo material y prestigio que éstas le otorgaban - entre fines del siglo XIX y principios del $X X$ se inició un proceso de institucionalización y profesionalización de la disciplina histórica. Sus miembros, a pesar de divergencias personales e institucionales, compartían una serie de acuerdos sobre la forma y características en que debía desarrollarse esta actividad. En primer lugar, algunos de carácter teórico-metodológico: La historia era una ciencia de carácter ideográfico e inductivo, porque su objeto está integrado por hechos, procesos y personajes únicos e irrepetibles y por lo tanto la posibilidad de conocerlos no se da a partir de categorías universales sino a través de sus contextos particulares. Practicada según un canon metodológico riguroso (aprendido de los maestros europeos Ranke, Altamira, Xenopol, Langlois y Seignobos, Berheim) que comprendía una serie de operaciones heurísticas y hermenéuticas, esta ciencia podía producir un relato objetivo - y por lo tanto verdadero - sobre el pasado. En segundo lugar, existía un extendido consenso sobre la necesidad de elaborar una historia del pasado nacional desde estas premisas teórico-metodológicas cuyo punto de partida era ciertamente la última etapa del período colonial y especialmente los sucesos de 1810, entendidos como el momento fundacional de la nacionalidad. El formato que mejor se adaptaba a este propósito era una historia nacional, de corte político-institucional, estructurada según el eje cronológico que no sólo 
permitía organizar los hechos en una sucesión diacrónica, sino que brindaba al relato un efecto de relación causal. Por lo general, éste era protagonizado por actores individuales, seres excepcionales que actuaban como motores del cambio histórico.

Finalmente, existía un acuerdo generalizado entre los historiadores (aunque unos lo practicaran más que otros) sobre las virtudes pedagógicas de la historia y la necesidad de "[...] Realizar la educación moral de la juventud con la enseñanza de la historia [...]" (LEVENE 1912), acercando al sistema educativo las investigaciones sobre historia argentina que se llevaban a cabo en los claustros académicos. Parte de los libros para el nivel medio que comenzaron a editarse en la primera década del siglo XX estaban escritos por jóvenes historiadores pertenecientes a esa generación, como Ricardo Levene, Rómulo Carbia, Diego L. Molinari o Emilio Ravignani, quienes más tarde serían reputados como conspicuos miembros de la Nueva Escuela Histórica. Sin embargo, esta profesionalización era más un horizonte de expectativas que una situación existente, y junto a estos historiadores profesionales convivían autores cuya autoridad para escribir manuales de historia emanaba de su prestigio en el campo literario o del desempeño de cargos públicos. Este es el caso de García Merou, personaje polifacético, poeta, ensayista y periodista, señalado por Adolfo Prieto como uno de los representantes mas destacados de la literatura de su generación, quien desempeño altos cargos públicos como Ministro de Agricultura y Embajador en EEUU durante el segundo gobierno de Roca y publicó una historia de la República Argentina de gran circulación en el nivel medio.

Podría suponerse que la formalización gradual del campo historiográfico, potenció un uso de la simbología patriótica y las imágenes del pasado acuñadas en los años inmediatamente posteriores a la Revolución de Mayo, no sólo destinadas a evocar pasados, sino más bien presentes y futuros. Fueron símbolos utilizados con el propósito de crear identidades colectivas, "argentinidad" como se proclamaba alrededor del Primer Centenario, ahí donde no existían o eran incipientes. Estas operaciones, destinadas a consagrar una memoria "pública" oficial se apoyaban en la retórica de la igualdad y la homogeneidad para construir una comunidad imaginada, modelizaban una norma para producir un ciudadano y al mismo tiempo diferenciarlo de aquellos que no lo eran (CASTRO GOMEZ 2000). Así, el pasado se celebraba en tanto caución o garantía de un futuro de "grandeza".

Aquella simbología decimonónica perduró más de medio siglo, así como la idea de una sociedad "crisol de razas", abierta y con movilidad ascendente. La simbología subsistió a pesar de que la Argentina del siglo XX demostró que aquel futuro era menos venturoso del que imaginaban los hombres del primer centenario, y el conflicto político y social marcó la mayor parte de la historia argentina reciente.

\section{La historia presentada por los libros de textos del centenario}

Ya desde los títulos de los libros (Lecciones de Historia Nacional, Historia de la Civilización Argentina) los autores adoptan un diseño para narrar la historia 
argentina comúnmente denominado historia tradicional, en el que aparecen condensadas buena parte de las características descriptas más arriba para la historiografía académica. El dispositivo para contar esta historia nacional pone el eje en la conformación y consolidación de un Estado y una Nación. El relato que explica este origen tiene límites temporales laxos; puede comenzar el recorrido en la colonia - y aún antes - y extenderse hasta el siglo XX. Son libros de Historia Argentina con muy escasas referencias al contexto internacional, lo mismo sucede con la dimensión americana, que está ausente como escala de análisis. ${ }^{4}$

En cuanto a los aspectos formales, los libros analizados presentan una diversidad bastante amplia. Los libros son en general extensos (de entre 200 y 400 páginas) y con gran cantidad de información. Sin embargo, existe un intento "didáctico" de hacer accesible la lectura a través de un armado que lo fragmenta en textos relativamente breves (dosificados en lecciones, por ejemplo), acompañado de imágenes y con la inclusión de algunas fuentes primarias. Levene incluye además textos de dos jerarquías diferentes; en un cuerpo de letra mayor el relato principal y en caracteres menores, textos secundarios que analizan en detalle enunciados del texto central o introducen otros aspectos no tratados en aquel. Por lo general despliegan a lo largo de un buen número de páginas los acontecimientos vinculados a la Revolución. En De Vedia, por ejemplo, hay cuatro lecciones dedicadas a los antecedentes y la quinta exclusivamente a la jornada del 25 de mayo. Errotaberea reserva todo un capitulo para desplegar cada una de las invasiones inglesas (capítulos XV y XVI), y dos capítulos íntegros a los días de la Revolución de Mayo (capítulos XVII y XVIII).

De todos modos, los libros están pensados más como material de estudio, de consulta para el hogar, que para ser trabajados en el aula y son valorados en función de la cantidad y veracidad de la información contenida. La mayoría incluye imágenes, pero con la idea de que éstas hablan por sí mismas, que cuentan lo que pasó, no como fuentes a las cuales interrogar. En el caso del texto de De Vedia, la inclusión de imágenes responde al propósito explícito de facilitar el aprendizaje y se fundamenta con argumentos que podríamos considerar didácticos como:

[...] la lectura es la tarea de imaginarnos el cuadro de lo que estamos leyendo [...] El conocimiento de ese hecho glorioso [la batalla de Maipú] quedara mas o menos claro en nuestra memoria: pero si leemos la descripción teniendo delante el cuadro de un artista que la haya representado con exactitud no olvidaremos jamás ni los detalles secundarios de la lectura correspondientes [...] (DE VEDIA 1913, p. V).

En relación al contenido, es común a todos los casos analizados el predominio de un relato basado en una sucesión cronológica de acontecimientos en general político-militares, ${ }^{5}$ con abundancia de anécdotas y centrado en

\footnotetext{
${ }^{4}$ Son historias en las que la nación tal y como quedó conformada a fines del siglo XIX se proyecta hacia atrás en el tiempo. Cuando se refieren a hechos que tienen lugar en otros espacios es en general como "causa externa" de lo que sucede en el Río de la Plata. Es el caso de la Revolución Francesa o del levantamiento del Alto Perú.

${ }_{5}^{5}$ Por lo general el discurso se circunscribe a los aspectos político- militares, a tal punto que, por ejemplo, no
} 
actores individuales (los próceres-héroes). ${ }^{6}$ En algunos casos estos actores no son individuos sino colectivos personificados, como las naciones, los pueblos o las instituciones. Por ejemplo, en el libro de Errotaberea, la segunda invasión inglesa resulta de la intención de Inglaterra de castigar a quienes la habían derrotado por la ofensa infligida en la primera incursión.

Otro rasgo compartido por la mayoría de los textos escolares analizados es la preocupación por la rigurosidad de los conocimientos a transmitir y por acercar a los alumnos la producción historiográfica generada en la universidad. Así, el Manual de Historia de la Civilización Argentina ordenado por Rómulo Carbia se presenta como un libro "[...] preparado con los materiales de la sección historia de la facultad de Filosofía y Letras de la UBA y con la cooperación de sus miembros $[\ldots]$ " para reparar uno de los efectos del Centenario que considera alarmantes: la proliferación de editores

[...] cuya temible inexperiencia los erigió en autoridad y cuyo mal entendido patriotismo sirvió de excusa para todos los yerros [...] generalmente están atrasados en medio siglo [...] [y presentan] lagunas, omisiones y hasta errores [...] (CARBIA 1917, p. 9, 14).

Un aspecto que interesa especialmente desde la perspectiva actual es el lugar dado a la explicación. Si bien es cierto que en los textos de este período predomina la narración es posible inferir algunos esquemas explicativos. Por ejemplo, en el caso de la Revolución de Mayo, bajo la pregunta central que apunta a identificar qué fue lo que realmente ocurrió, y que se resuelve mediante un relato cronológico minucioso de los sucesos, subyace la idea de que esa secuencia cronológica no solo ordena, sino que en alguna medida explica los hechos. En el texto de Carbia la Revolución tiene una etapa invisible que comienza en 1806 y una pública que se manifiesta en mayo de 1810. En el de Levene, la Revolución tiene antecedentes externos (La Revolución Norteamericana y la Francesa) e internos considerados en un plazo realmente corto, como son la Representación de los Hacendados, el Motín de Alzaga (enero 1809) y la fracasada Revolución del Alto Perú (mayo 1809). En ambos casos estos esquemas funcionan como una explicación.

Por su parte, De Vedia plantea los hechos como el resultado del conflicto entre las Tendencias inglesa, española, francesa y argentina. Las nacionalidades llegan a funcionar como actores en un desarrollo que por momentos tiene un desenlace fatal. Derrotadas la tendencia francesa y la inglesa, en las invasiones inglesas y los años subsiguientes, "[...] Quedaron en pie, solamente, la influencia española en el gobierno, y la tendencia argentina en el alma indomable de los criollos [...]" que necesariamente tenía que imponerse (DE VEDIA 1913, p. 10). Para subrayar la veracidad de los argumentos introduce detalles. La

aparece mención alguna a la Revolución Industrial cuando se tratan las invasiones inglesas (solo la superioridad naval). Para un análisis detallado de estos tópicos nos permitimos remitir a LEWKOWICZ; RODRÍGUEZ (2009).

${ }^{6}$ Es un conjunto muy numeroso de individuos excepcionales, no sólo los próceres habituales, como los miembros de la Primera Junta o San Martín, sino también cuadros medios de la política y los ejércitos de los que se destaca nombre, apellido y cargo desempeñado. 
revolución es el resultado de un plan premeditado de independencia nacional sostenido con absoluta unanimidad por los revolucionarios. Sin embargo, en los momentos decisivos, junto a los héroes está la acción del pueblo como fuerza desequilibrante. Así "[...] Entre la gestión atemperadora de los políticos dirigentes y la influencia española se interpuso [...] en un sublime estallido de sacrosanto entusiasmo patriótico, la franca e impetuosa decisión del pueblo [...]" (DE VEDIA 1913, p. 25). Con estos actores, organiza una cronología con profusión de hechos fechados al detalle y de nombres propios de personas y lugares, con fragmentos de diálogos y de fuentes, como la historia escrita por Mitre o las invitaciones para el cabildo abierto del 22 de mayo de 1810.

En el caso de García Merou, en un relato con ribetes de tipo conspirativo y profusión de nombres propios, descripciones de lugares, tropas y pertrechos militares, cobra especial relieve la participación unánime del conjunto de la población, incluyendo a mujeres, niños y ancianos en la Defensa y Reconquista, así como a la "inmensa multitud" que acompaña las jornadas decisivas de mayo, pues "[...] La situación que se produjo después de la victoria [frente a los ingleses] fue el primer síntoma de la agitación revolucionaria que debía realizar la emancipación del Río de la Plata [...]" (GARCÍA MEROU 1922, p. 332). Como nota distintiva, cabe destacar que dedica algunos párrafos a registrar los cambios que se habían producido en el Río de la Plata sobre todo al crecimiento económico y demográfico, ausentes en otros autores. Por lo demás, su esquema de causas externas e internas es muy similar al desarrollado por Levene.

En los libros coexisten contenidos propiamente históricos con otros que hoy consideraríamos de otra naturaleza, por ejemplo, alusiones a los símbolos patrios o la oración para la jura de la bandera. La yuxtaposición de estos dos elementos es coherente con la finalidad de índole identitaria asignada a la enseñanza de la historia - y a la historiografía en general - en ese período.

Los relatos desplegados en los textos tienen una fuerte carga moral y moralizante. Los grandes hombres encarnan el espíritu nacional y son a la vez un modelo a imitar, pues reúnen todas las virtudes y ninguno de los defectos de los seres humanos. Tienen la misión de poner en acto toda la potencia de la nación, esto es, consolidar el futuro de grandeza y prosperidad que estaba prefigurado desde los orígenes. A modo de ejemplo puede señalarse la cobardía del Virrey Sobremonte en contraste con el heroísmo de los criollos ${ }^{7}$, o la apología de Washington introducida por Levene. En todos los autores hay una adjetivación sobrecargada cuyo objeto parece ser asegurarse un impacto de adhesión emocional en el lector. De Vedia introduce, además, máximas como "[...] Cuando se trata de la Patria no hay amenaza capaz de contener a los patriotas [...]" (DE VEDIA 1913, p. 14).

Otra cualidad de estos libros producidos en torno al Centenario, que resulta práctica para la enseñanza, es el carácter cierto y acabado que le otorgan al saber

\footnotetext{
7 Una adjetivación similar hay en el texto de Errotaberea, además de referenciarse como el primer hecho glorioso de las armas criollas. Las invasiones inglesas se narran con gran despliegue de detalle de individuos, lugares, avances y retrocesos. En De Vedia la sublevación del Alto Perú es denominada "sacrosanto movimiento"
} 
histórico y por lo tanto del saber a enseñar. Una vez estabilizada una imagen de cada porción de ese pasado y corroborada por sus respectivas fuentes, lo que resta como tarea para la educación es simplemente asegurar su transmisión lo más completa e inalterada posible. Al mismo tiempo ese conocimiento acabado se plantea como conocimiento construido. Incluso se presentan debates, por ejemplo, De Vedia introduce el debate entre historiografías nacional

[...] Algunos historiadores españoles y franceses han sostenido la tesis de que los argentinos no pensaron en independizarse sino en organizar un gobierno [...] [que tendría] existencia solo mientras España no reorganizara el suyo. Esta tesis es banal. Los argentinos, como todos los pueblos americanos soñaban con ser libres [...] (DE VEDIA 1913, p. 19). ${ }^{8}$

Para De Vedia la existencia de este sentimiento en todas las colonias americanas es lo que explica la simultaneidad de los procesos independentistas.

Es posible señalar, a propósito de los objetivos identitarios de la enseñanza de la historia para el nivel medio, una cierta continuidad con los señalados para el nivel primario. Sin embargo, esta continuidad está apoyada en una perspectiva diferente. Los profesores y autores de libros para el nivel medio tienen como destinatarios estudiantes que ya pasaron por la escuela primaria, es decir que pueden pensar en una serie de tópicos como ya dados y avanzar en otros que los complementen a partir de un aprendizaje riguroso de la historia. Sin embargo, este conocimiento "riguroso" del pasado también tiene el sentido de profundizar el patriotismo y la identidad, pero en adelante no solo como una adhesión emocional sino también como fruto del conocimiento de su historia, producto de la erudición.

\section{El Bicentenario: libros de texto, historia y educación}

Las reflexiones a las que convocó la proximidad del bicentenario carecieron del optimismo que trasuntaban las de cien años antes. La sociedad había cambiado mucho, también las expectativas sobre el futuro y las formas de evocar el pasado. Entre los historiadores ya hacía algunas décadas que los marcados consensos epistemológicos y metodológicos sobre la disciplina habían cedido paso a una gran heterogeneidad en los modos de entender cómo hacer y enseñar historia. El estallido de estos paradigmas interpretativos estabilizados desde fines del siglo XIX, no dio lugar a la emergencia de otro que ocupara su lugar. Más bien el signo de estos tiempos parece ser la ausencia de paradigmas dominantes. Si ahora la historia como ciencia tiene el objetivo de centrarse en explicar los procesos históricos, los alcances de esa indagación son menos claros. Aún sin caer en las posiciones extremas que niegan a la historia toda posibilidad de conocer el pasado, convirtiéndola en pura retórica, es indudable que las lecturas del pasado son múltiples y los puntos de vista del sujeto variados. Hay cierto relativismo en toda interpretación del pasado.

\footnotetext{
8 Nótese el uso del gentilicio "argentinos" para la época de 1810. En otro lugar agrega que "con el primer conquistador que vino a América entró el germen de la independencia americana [...]".
} 
Otras transformaciones acompañaron también estas reflexiones teóricas - y ciertamente fueron influidas por éstas -. Por un lado, una ampliación extraordinaria del repertorio de problemas, temas y formas de abordaje de las investigaciones históricas. En las últimas décadas las fronteras del territorio de investigación de los historiadores se expandieron hasta alcanzar nuevos temas, como la vida cotidiana, la infancia, los olores, los sabores, la producción, circulación y consumo de bienes culturales, los lugares de la memoria, la lectura, las prácticas culturales, los ritos y las creencias, las formas de sociabilidad; nuevos sujetos como las mujeres, los niños, las minorías; nuevas formas de abordaje conceptuales o metodológicas como la microhistoria, la historia de las prácticas o la historia de los conceptos. Por otro, esta vitalidad historiográfica se conjugó con la revalorización del sujeto y sus acciones - opacadas desde mediados del siglo XX por el auge de las aproximaciones macroestructurales, el énfasis en la construcción de modelos explicativos y el diálogo con otras ciencias sociales "modelos" de cientificidad -, y con la preocupación de los historiadores por las formas de difusión del conocimiento producido en la disciplina, por la comunicabilidad más allá de los muros de la academia. Las formas de la divulgación se han convertido en un fenómeno al que en los últimos años se le ha prestado una atención creciente.

Todos estos procesos, pusieron en debate y reformularon la relación de los historiadores con la sociedad y el Estado en un doble sentido. Si los historiadores han apartado su tarea de la generación de mecanismos identitarios, haciendo hincapié por el contrario en el carácter inventado de las tradiciones nacionales, también es cierto que desde el Estado tampoco se le ha pedido a la historia desempeñar ese papel.

Estas transformaciones afectaron a la historia enseñada en las escuelas. A diferencia de lo ocurrido en las décadas anteriores - pero en consonancia con lo reseñado para el momento del centenario ${ }^{9}$ - en la última del siglo XX las nuevas tendencias historiográficas se trasladaron más o menos rápidamente al sistema educativo. Entre otras razones, la gran cantidad de profesores universitarios e investigadores que durante los años ' 90 formaron parte de los elencos de funcionarios y técnicos del Ministerio de Educación, de los planteles de autores de las editoriales de libros de texto, o de los grupos de capacitadores docentes de los programas nacionales y provinciales de apoyo a la reforma educativa, fueron decisivos para ello.

El sistema educativo tampoco era el mismo que cien años antes. A lo largo de su historia, la educación secundaria registraba importantes transformaciones. De la mano de la significativa ampliación de la matrícula y el cambio en la composición social de docentes y alumnos, cambiaba también la naturaleza misma del nivel. Lejos de los propósitos de socialización de élites dirigentes que

\footnotetext{
${ }^{9}$ Es interesante destacar que tanto el momento Centenario como el momento Bicentenario las relaciones entre historiografía académica y sistema educativo fueron estrechas, vínculo facilitado por la convergencia de autores, profesionales y funcionarios en ambos ámbitos. Esto contrasta con las décadas que median entre estos dos momentos (o por lo menos entre la década de $1940^{`}$ y fines de los años $1980^{\prime}$ ), donde el divorcio entre mundo académico y sistema educativo fue pronunciado tal como señalan Hilda Lanza y Silvia Finocchio en su libro Curriculum presente, ciencia ausente (LANZA; FINOCCHIO 1993, v. 3).
} 
signaron sus comienzos, la educación media se generalizaba hasta alcanzar en los años previos al bicentenario la obligatoriedad. ${ }^{10}$

El retorno al régimen democrático en 1983 luego de 7 años de dictadura, supuso importantes cambios en la sociedad. En el sistema educativo significó repensar entre otras cosas los contenidos que se enseñaban y la inclusión de otros nuevos, el concepto de ciudadanía que se quería transmitir, los procesos de enseñanza, aprendizaje, todo esto en un clima de apertura y recepción de novedades teóricas y metodológicas desarrolladas en otros contextos nacionales. Estos procesos se profundizaron en la década siguiente y se combinaron con transformaciones en la estructura y características del sistema educativo. En diciembre de 1991 por Ley 24.049 el Ministerio de Cultura y Educación traspasó a las provincias los niveles medio y superior no universitario, concluyendo el proceso de transferencia de los servicios educativos iniciado en los años '60. En abril de 1993 se sancionó la Ley 24.195, Ley Federal de Educación y en diciembre del 2006 fue reemplazada por la nueva Ley Nacional de Educación, actualmente vigente. ${ }^{11}$

\section{La historia presentada por los libros de textos en torno del bicentenario}

Los libros de texto para la enseñanza de la Historia editados en la última década para el nivel medio no toman la historia de la nación como eje articulador del relato. No solo ha sido abandonado ese eje sino que, además no fue reemplazado por otro sino por una diversidad de ejes: político, social, económico, cultural, las ideas. Los libros de texto asumieron las nuevas concepciones de la historia desplegadas en la historiografía académica a lo largo de las últimas décadas y también los cambios en las finalidades de la enseñanza de la disciplina en los distintos niveles del sistema educativo. En conjunto, todos ellos presentan una historia procesual donde los protagonistas son actores sociales colectivos. No se reducen a la cronología, sino que intentan desplegar las complejidades del tiempo histórico. En lugar de ofrecer información supuestamente objetiva sobre el origen y desarrollo de la Nación, intentan responder a interrogantes diversos formulados desde el presente y trabajar con la subjetividad. Junto a esto, ponen énfasis en presentar al conocimiento histórico como un resultado provisorio, aunque no arbitrario, y en familiarizar a los estudiantes con los problemas de la operación histórica y el oficio del historiador. A esto se suma una atención

\footnotetext{
$\overline{10}$ La ley de Educación Nacional 26206, sancionada en 2006 dispuso la obligatoriedad de la educación secundaria. ${ }_{11}$ Para el sistema educativo en su conjunto las modificaciones fueron múltiples. Aquí nos interesa señalar las relacionadas con los contenidos curriculares que introducidas en la LFE se mantuvieron inalteradas en la LEN: Se diseñó una política curricular de definición en el nivel central, pero de aplicación descentralizada por parte de cada una de las jurisdicciones, lo que significó la necesidad de establecer un primer nivel de especificación curricular acordado entre autoridades nacionales y provinciales referido a que enseñar, los Contenidos Básicos Comunes $(\mathrm{CBC})$. En relación a este último punto, la reforma comenzó por producir una transformación, modernización y actualización de los contenidos de las ciencias sociales se enfatizó la necesidad de orientar la enseñanza hacia la explicación de los procesos sociales como resultado de las relaciones sociales, políticas, económicas y culturales establecidas entre los grupos humanos en el tiempo y el espacio, con énfasis en las épocas más recientes y en el contexto argentino. La contemporaneidad, la realidad social presente, encuentra así en el análisis del ayer una de sus claves de interpretación. Por este motivo, otro de los ejes de estos nuevos contenidos son los procedimientos relacionados con la comprensión y la explicación de la realidad social, es decir con el modo en que las disciplinas del campo de las ciencias sociales producen conocimientos.
} 
especial a las cuestiones pedagógicas y didácticas y una voluntad de constituirse en el apoyo del trabajo docente en el aula.

Los autores de los textos analizados son en su mayoría egresados de Universidades Nacionales que desarrollan paralelamente tareas de docencia e investigación en ámbitos académicos. Se evidencia una voluntad de acercar las transformaciones operadas en la historiografía y en el rol de la historia y los historiadores a públicos más vastos - en este caso estudiantes - Por su parte, las empresas editoriales hacen desde sus propios "staff" aportes pedagógicos. Como resultado, la figura del editor y el peso de la editorial como creadores cobraron especial relevancia. ${ }^{12}$

Como resultado de este conjunto de transformaciones cambiaron los contenidos y formatos de los libros de texto y también la función misma del texto escolar. Del uso tradicional, corriente en tiempos del Centenario y vigente durante décadas, que lo situaba básicamente como material de estudio; se pasó a considerar el texto escolar como herramienta del trabajo cotidiano del aula. En relación con este nuevo rol se valorizan características diferentes de los libros de texto, como la presencia de fuentes primarias, ${ }^{13}$ de textos de especialistas, las actividades que proponen, las imágenes, la inclusión de láminas desplegables, los dossiers sobre temas especiales y análisis de casos, atlas para trabajar, cuadros estadísticos y mapas, los proyectos de investigación que acompañan al libro etc. A diferencia de los textos del Centenario en la actualidad, y desde hace tiempo, junto a los textos escolares frecuentemente se produce otro para el docente, que se entrega en forma gratuita y que suele incluir mapas conceptuales, repertorios bibliográficos y propuestas didácticas para cada tema. Los textos actuales incluyen, además, otras "aperturas" y vinculaciones como la sugerencia de sitios de Internet para visitar, noticias, la exploración en museos (virtuales y reales), listados de películas tanto documentales como cine de ficción, etc.

Los libros ofrecen textos de distintas jerarquías, consignas para el trabajo de los alumnos, fuentes, imágenes, así como aspectos de la construcción del conocimiento histórico y de los debates historiográficos. ${ }^{14}$

El tratamiento de la Revolución de Mayo de 1810 en estos libros de texto es precedido por un amplio desarrollo de otros procesos que se dan simultáneamente como la Revolución Industrial, La Revolución Norteamericana y la Revolución Francesa, y de un pormenorizado análisis de la sociedad, la economía y la política en las colonias españolas de América. En el caso del publicado por la editorial Aique, bajo los títulos "La situación de las colonias americanas a principios del siglo XVIII", "La reorganización de los imperios iberoamericanos" y "La resistencia a las reformas" se ofrece un amplio panorama del contexto hispanoamericano. El libro de Kapelusz Norma incluye un capítulo entero dedicado a la "Crisis del

\footnotetext{
${ }^{12}$ Consecuencia de estos cambios es que desde hace unas dos décadas es muy común que tanto docentes como alumnos conozcan a los libros de texto por la editorial y no por los autores que los escribieron.

${ }^{13}$ La presencia de fuentes no es una novedad, pero sí la función que se les asigna y su relevancia dentro del texto.

${ }^{14}$ En el texto de Aique, por ejemplo, se incluye una propuesta de trabajo acerca de "Discusiones y debates

sobre la organización política de los nuevos países hispanoamericanos en las primeras décadas del siglo XIX.
} 
orden colonial español" y uno a "Revoluciones y guerras de independencia". En este último, se desarrollan la revolución de Venezuela y de Nueva Granada $y$, finalmente en un espacio acotado los acontecimientos de mayo de 1810 en Buenos Aires. Además, a modo de integración de contenidos, ofrece como tema especial "las mujeres y los niños en las revoluciones". Esto último se fundamenta en que "[...] En las revoluciones europeas y americanas [...] participaron en distintos papeles mujeres y niños. Todos ellos formaron parte de procesos de gran movilización social que transformaron las estructuras de las sociedades en las que vivían [...]" (RIZZI et al. 2009, p. 102). ${ }^{15}$ En Buonome et al. (2010) se selecciona el caso de la independencia de Cuba para profundizar ofreciendo un espacio considerable - 3 carillas - que contempla aspectos económicos y sociales además de los específicamente políticos. También se propone un trabajo de análisis comparativo entre los procesos de independencia en, por ejemplo, el Río de la Plata y la Gran Colombia. En Carrozza et al. (2010) la independencia en el Río de la Plata constituye un capitulo independiente, pero está antecedido por uno dedicado al orden tardocolonial, uno a las revoluciones inglesa y francesa, un tercero a las revoluciones hispanoamericanas en el que se abordan los casos de Venezuela, la Gran Colombia, Perú, México y Brasil y un trabajo de análisis comparativo entre el Rio de la Plata y México. Respecto del espacio dedicado a la Revolución, el libro de Carrozza et al. merece una mención aparte. En éste hay un capítulo entero de 15 páginas dedicado a la Revolución de Mayo. No sólo llama la atención por su extensión sino porque también despliega con mayor detalle que otros textos, los cambios políticos y da cuenta de un número muy considerable de actores individuales. En contraposición, la independencia del Río de la plata y la Primera Junta ocupan mucho menos espacio en otras propuestas - una pagina en el caso del libro de Alonso, M. E., J. Blanco et al. (2003) y dos páginas en Burucua J. E. (2006) - así como la situación en el interior del Virreinato (una pagina en ambos casos) diferenciando territorios, por ejemplo, Córdoba, Salta, la Banda Oriental, Paraguay y el Alto Perú.

Todas las propuestas contemporáneas tratan las cuestiones relativas al Río de la Plata en estrecha relación con el contexto americano y mundial. La Revolución en el Río de la Plata se presenta como caso dentro de un proceso a escala americana desencadenado por la caída de los imperios ibéricos y ligados a su vez al movimiento juntista peninsular. Las consecuencias de la revolución y la guerra también son objeto de análisis a escala continental, y son estudiadas en sus aspectos económico, social y político.

En todos los textos analizados, lejos de inaugurar la vida de la nación, la revolución aparece como un momento de transformaciones trascendentes, de resultado incierto, en el que intervienen actores diversos con intereses también diversos. Lo que guía el análisis de la esfera política, a partir de allí, es la idea de las dificultades que surgieron para la organización de un Estado, la falta de unanimidad y las resistencias a la organización de un gobierno central.

\footnotetext{
${ }^{15}$ En Rizzi et al., los ecos de las transformaciones en la historiografía de las últimas décadas son muy claras. Además de esta consideración de diversidad de actores vale la pena subrayar el sub título elegido para la obra, La Argentina en el largo siglo XIX.
} 
El libro de la editorial Tinta Fresca (CHIARAMONTE et al. 2006) pensado para los estudiantes de los últimos años de la escolaridad secundaria, ofrece un desarrollo mucho más extenso de los temas en cuestión. El periodo 1780-1820 se desarrolla en dos capítulos completos, el primero más enfocado a los aspectos políticos e ideológicos mientras que el segundo se complementa con el tratamiento de las transformaciones socioeconómicas. En su conjunto totalizan 60 páginas. ${ }^{16}$ La escala latinoamericana tiene una presencia muy fuerte. Al igual que en el de la editorial Aique (ALONSO et al. 2003), la revolución en el Río de la Plata es resultado de un proceso que se desencadena por la disolución del imperio. Las invasiones inglesas están inextricablemente ligadas a la Revolución Industrial y, entre sus efectos se subrayan, lejos del despertar de una identidad criolla, el proceso de la militarización y politización de amplias capas de la población y la organización de grupos con ideas revolucionarias. Los acontecimientos, protagonizados por sujetos individuales y colectivos con ideas e intereses diversos tienen resultados que no pueden determinarse a priori y, tras la Revolución, la guerra impacta en todos los aspectos de la sociedad.

En todos los casos se apunta al discurso explicativo. La información se brinda con el objeto de posibilitar la elaboración de explicaciones multicausales. ${ }^{17}$ Ninguno de los textos analizados presenta a la Revolución como un proceso cuya realización tenía fatalmente que registrarse. Ninguno postula la existencia de un proyecto revolucionario definido desde los comienzos, ni la unanimidad entre los grupos que participaron de las jornadas de mayo. Los actores individuales son tratados en forma simultánea a la introducción de actores colectivos y diversos. No se hacen apreciaciones ni juicio moral alguno. Todos consideran la conformación fuertemente estratificada de la sociedad y prestan especial atención a la categoría de vecino para evitar anacronismos.

\section{A modo de balance: los centenarios, los historiadores, los libros de texto y sus contextos}

La elección de los dos momentos analizados no es casual, aunque la indagación no se haya ceñido estrictamente al año de la conmemoración sino extendido a la década que antecede y sucede al centenario y bicentenario de la Revolución de Mayo. Consideramos que alrededor de las conmemoraciones se activan un conjunto de fenómenos claramente colocados en el cruce de las dimensiones cognitiva, instrumental y memorial. Son acontecimientos, en

\footnotetext{
${ }_{16}$ La propuesta de Tinta Fresca para los estudiantes de lo que entonces constituía el Tercer Ciclo de la Educación General Básica (BURUCUA 2006) dedica un capítulo a las revoluciones de independencia en América Latina y enmarcado allí sólo 4 páginas para el caso del Río de la Plata que cubren hasta la Declaración de la Independencia en 1816. El resto del capítulo desarrolla otros casos nacionales.

17 También reflejado en consignas de actividades propuestas. Por ejemplo, en el texto de editorial Aique "[...] ¿Por qué la oposición más fuerte al movimiento revolucionario en el Río de la Plata estuvo localizada en las ciudades del interior del antiguo virreinato? (ALONSO et al. 2003, p. 151) Reunidos en grupos discutan por qué la mayoría de los grupos dirigentes [...]. Dieron marcha atrás con algunas medidas... ¿Como la abolición de la esclavitud y de los tributos indígenas [...]?" (ALONSO et al. 2003, p. 149) O en el texto de la editorial Tinta Fresca: "...Comparen las causas que condujeron a la independencia de los Estados Unidos con las que posibilitaron la independencia de las naciones latinoamericanas [...]" (BURUCUA 2006, p. 213).
} 
el sentido otorgado por Arlette Farge, que permiten acercarnos al análisis de las dinámicas sociales, políticas y culturales que una comunidad exhibe en un contexto históricamente situado, y por lo tanto sensibles a un análisis atento a la cultura histórica y los usos de la historia (GARGE 2002; DEVOTO 2015).

En ambos momentos se registran relaciones estrechas entre imágenes del pasado construidas por la historiografía académica y las que aparecen en los libros de texto. También es común a ambos períodos la voluntad de los historiadores profesionales de estrechar lazos con el sistema educativo a fin de corregir errores, difundir las últimas innovaciones y superar el atraso bibliográfico. Lo mismo puede decirse de la fuerte coherencia entre los contenidos de enseñanza y ciertos consensos básicos en el campo intelectual sobre la sociedad y sus valores. ${ }^{18}$

La cronología como eje organizador excluyente de los tiempos del Centenario ha cedido su lugar a la periodización y el despliegue de las diversas dimensiones del tiempo histórico. Aunque cabe subrayar que a veces en los textos actuales la periodización aparece naturalizada. Los sujetos de la historia resultan contrastantes en uno y otro momento. Si la argentinidad aparecía como sujeto hace cien años, hoy la Argentina se presenta como realidad histórica compleja a explicar. Por lo general se ha abandonado el hábito de personificar a las naciones, ciudades y regiones. El relato protagonizado por grandes hombres seguidos unánimemente por la nación o el pueblo, propio del Centenario, también ha sido dejado de lado.

Se ha pasado de las certezas a las incertidumbres. De un saber cerrado y objetivo a un saber en construcción, siempre provisorio, cambiante, subjetivo que obliga a enseñar en un contexto de falta de certezas. Si no hay objetividad ni un "paquete cerrado" a transmitir a las nuevas generaciones, habrá saberes presentados como estado actual del conocimiento, ideas que tienen consenso entre los especialistas o por el contrario, polémicas y controversias persistentes. La renuncia a una supuesta objetividad impone la necesidad de dar cuenta de múltiples miradas.

En contraste con lo observado en los textos escolares del Centenario, en los del Bicentenario se presenta el proceso independentista más allá de los sucesos que tienen a Buenos Aires como escenario o como lugar desde el que parten las iniciativas. Así, distintas regiones son presentadas con sus propias características económicas y sociales y conforman escenarios de conflictos diversos que definen a su vez sus propios actores.

Los libros del Centenario requerían de la lectura de corrido, en sintonía con el relato y la linealidad del acontecer histórico. Los textos escolares actuales invitan al lector a construir un texto (toda lectura es una escritura). Convertidos en herramientas de trabajo para el aula, los libros de texto de hoy invitan al

\footnotetext{
18 El foco puesto alrededor de los centenarios, deja en sombras el estudio del período que media entre ellos, en el que es perceptible, tal como señalamos, una tendencia de sentido inverso a la descripta, donde la brecha entre historiografía e historia escolar se ensancha. Intuimos que esa distancia está relacionada con los nuevos rumbos que adopta la historiografía profesional y su escasa utilidad como contenido para la historia escolar y también con cierta inercia que se registra en el sistema educativo, aunque estas cuestiones deberían ser objeto de un análisis pormenorizado.
} 
lector individual y colectivo a desplegar estrategias y recorridos diferentes (mediados o no por la intervención del docente).

Un comentario aparte merece las imágenes incluidas en los textos escolares para el desarrollo de los temas analizados. En los textos del Centenario son escasas $^{19}$ y predominan los retratos y las escenas de batallas. Las imágenes que se reproducen en los libros escolares de hoy son en muchos casos las mismas u otras de naturaleza semejante, aunque en mayor cantidad y variedad. De todos modos, con frecuencia lo escueto de los epígrafes y las pocas referencias a autores y contextos de producción dan lugar a que prevalezca su naturalización. Creemos que en este sentido sería deseable revisitar las imágenes de nuestros libros de texto con una mirada que las enriquezca, pensándolas como parte de un discurso histórico, un proyecto elaborado en gran medida también en torno del centenario. ${ }^{20} \mathrm{~A}$ diferencia de lo que pasa hoy con los temas políticos que son ilustrados a la manera del Centenario, con retratos, escenas de batallas y de edificios, cuando se tratan aspectos de la economía y la sociedad, en cambio, las ilustraciones ofrecen una variedad mucho mayor, con escenas de la vida cotidiana en el hogar y en el mundo del trabajo, de las ciudades, de distintos grupos sociales, etc. Otra "novedad" es la inclusión de abundante información cuantitativa (muchas veces en gráficos o en cuadros de doble entrada) sobre todo referida a la población, el comercio y la producción.

Finalmente, sería interesante considerar qué pasa cuando estas perspectivas desplegadas en los libros de texto actuales son desarrolladas en la práctica docente. El impacto de los consensos disciplinares alcanzados en ambos períodos permearon rápidamente la propuesta editorial de libros de texto, facilitado por el rol jugado por los historiadores en su producción. Menos investigado está por las dificultades que entraña su aprehensión y estudio- qué pasó y qué pasa con el desarrollo efectivo de estos temas en el aula.

\section{Referencias bibliográficas}

ERROTABEREA, M. Lecciones de Historia Nacional. Buenos Aires: Talleres Gráficos de J. Sesé, 1910.

LEVENE, R. Lecciones de Historia Argentina. Buenos Aires: Lajouane, 1912. TORRE, J. M. ; CARBIA, R. ; RAVIGNANI, E. ; MOLINARI, D. L. Manual de Historia de la Civilización Argentina. Buenos Aires: Franzetti, 1917.

GARCIA MEROU, M., Historia de la República Argentina. Buenos Aires: Estrada, 1922.

DE VEDIA, E. Lecciones Argentinas. Buenos Aires, 1913.

\footnotetext{
19 No había una producción considerable de obras artísticas de carácter histórico antes del Centenario. De hecho, es en torno de la celebración que se desata la producción en mayor escala. Ver, por ejemplo, la labor de Carranza desde su lugar de director del Museo Histórico Nacional como comitente y asesor de artistas como Pedro Subercasseaux.

20 Para posibilitar este trabajo deberían introducirse mas referencias a cuestiones del contexto de producción, los artistas, las ideas que se querían expresar y los modos de hacerlo, etc.
} 
ALONSO, M. E. et al. Ciencias Sociales 8. Buenos Aires: Aique, 2003.

BURUCUA, J. E. et al. Historia Moderna. Europa y América (1450-1850). Buenos Aires: Tinta Fresca, 2006.

ChIARAMONTE, J. C. et al. Historia I. Buenos Aires: Tinta Fresca, 2006.

RIZZI, A. et al. Una historia para pensar. La Argentina en el largo siglo XIX. Kapelusz-Norma, 2009.

BUONOME, J. et al. Historia moderna y contemporánea americana y argentina siglos XV a XIX. Tinta Fresca 2010

CARROZZA, W. et al. Historia. La Argentina, América Latina y Europa entre fines del siglo XVIII y comienzos del siglo XX. Santillana, 2010.

AISENBERG, B. La historia escolar en la Argentina: continuidades del modelo de la 'identidad nacional' e intentos de ruptura. Reseñas de enseñanza de la Historia. APEHUN, n. 5, sep. 2007.

AMEZOLA, G. de. El pasado servicial. Elementos revisionistas en los textos de Cultura Ciudadana (1952-1955). Clío \& Asociados, n. 1, 1996. La historia argentina reciente en los manuales escolares. Segundo Seminario Internacional: Textos escolares en Iberoamérica, Avatares del pasado y tendencias actuales, Quilmes, Universidad Nacional de Quilmes, 1997.

Esquizohistoria. La Historia que se enseña en la escuela, la que preocupa a los historiadores y una renovación posible de la historia escolar. Buenos Aires: Libros del Zorzal, 2008.

FARGE, A. Penser et definir l'événement en histoire. Approche des situations et des acteurs sociaux. Terrain. Revue d'ethonology de I'Europe, n. 38, 2002.

BRASLAVSKY, C. Los libros de texto en su contexto: Argentina 1975-1989. En RIECKENBERG, M. (comp.). Latinoamérica: Enseñanza de la historia, libros de texto y conciencia histórica. Buenos Aires: Alianza; FLACSO; G. Eckert Institut, 1991.

Los usos de la historia en la educación argentina: con especial referencia a los libros de texto para las escuelas primarias (1853-1916). Buenos Aires: FLACSO Argentina, 1992 (Serie Documentos e Informes de Investigación, n. 133).

CARRERAS ARES, J. J.; FORCADELL ALVAREZ, C. Usos públicos de la historia. Madrid: Marcial Pons, 2003.

CASTRO GOMEZ, S. Ciencias sociales, violencia epistémica y el problema de la 'invención del otro'. En: LANDER, E. (comp.). La colonialidad del saber: eurocentrismo y ciencias sociales. Perspectivas Latinoamericanas. Buenos Aires: CLACSO, 2000. 
CHERVEL, A. Historia de las disciplinas escolares. Reflexiones sobre un campo de investigación. Revista de Educación, n. 295, 1991.

COLOTTA, P.; CUCUZZA, H.; SOMOZA, M. Texto y lecturas escolares durante el primer peronismo. En: CUCUZZA, H. (dir.). Estudios de Historia de la Educación durante el primer peronismo. 1943- 1955. Buenos Aires: Los libros del Riel, 2001.

CORA, G.; RODRIGUEZ, M. Construyendo la "Nueva Argentina". Cultura Ciudadana y la consolidación de la política educativa del peronismo (19521955). Espacio, Tiempo y Educación, v. 2, 2015.

CUESTA FERNANDEZ, R. Sociogénesis de una disciplina escolar: la historia. Barcelona: Pomares-Corredor, 1997.

CUCUZZA, H. Yo argentino. La construcción de la Nación en los libros escolares (1873-1930). Buenos Aires: Miño y Dávila, 2007.

; SOMOZA, M. Representaciones sociales en los libros escolares peronistas. Una pedagogía para una nueva hegemonía, en OSSENBACH G. y SOMOZA M. Los manuales escolares como fuente para la Historia de la Educación en América Latina. Madrid: UNED, 2001.

; PINEAU, P. (dirs.). Para una historia de la enseñanza de la lectura y la escritura en Argentina. Del catecismo colonial a 'La razón de mi vida'. Buenos Aires: Miño y Dávila; Universidad Nacional de Luján, 2002.

DEVOTO, F. Idea de nación, inmigración y cuestión social en la historiografía académica y en los libros de texto en Argentina. Propuesta Educativa, n. 8, 1993.

. En torno a un problema: la enseñanza de la historia en el sistema escolar, en TENTI FANFANI E. (comp.). Diversidad cultural, desigualdad social y estrategias de políticas educativas. Buenos Aires: IIPE-UNESCO, 2009.

- Conmemoraciones poliédricas: acerca del Primer Centenario en la Argentina, en PAGANO N., RODRIGUEZ M. (comps.). Conmemoraciones, patrimonio y usos del pasado. La elaboración social de la experiencia histórica. Buenos Aires: Miño y Dàvila, 2014.

DOBAÑO, P., RODRIGUEZ, M. Los contenidos de los libros de texto escolares de historia y ciencias sociales. 1983-2006. En: Textos escolares de historia y ciencias sociales. Santiago de Chile: Ministerio de Educación, 2009.

EGGERS BRASS, T. Los libros de texto y la enseñanza de la historia reciente. Revista de Historia Bonaerense, n. 31, 2006.

GALLERANO, N. (ed.). L'uso pubblico della storia. Milan: F. Angeli, 1995.

GVIRTZ S., BARREIRO G., Patria y ley en la construcción de la ciudadanía. Los libros de lectura y los manuales de Instrucción Cívica en la escuela primaria argentina: 1870-1930. Veritas, v. 43, n. especial, 1998. 
HARTOG, F., REVEL, J. (eds.). Les usages politiques du passè. Paris: EHESS, 2001.

HUARTE, G.; VAN DER HORST, C. Historiografía y enseñanza de la Historia en Argentina (1880-1910). En: CASTRO, I. (coord.). Visiones latinoamericanas. Educación, política y cultura. México: CESU; UNAM; Plaza y Valdés, 2002.

KAUFMANN, C. Producciones sobre textos escolares argentinos: hitos, tendencias y potencialidades. Anuario de Historia de la Educación, n. 4, 2002/2003. . (dir.). Dictadura y educación. Los textos escolares en la historia argentina reciente. Buenos Aires: Miño y Dávila, 2006. t. 3.

. "La quiebra del orden constitucional". La Dictadura en los textos de civismo (1983-1986). En: ASCOLANI, A. (comp.). El Sistema Educativo en Argentina. Civilidad, derechos y autonomía, dilemas de su desarrollo histórico. Rosario: Laborde Libros, 2009.

Manualística Escolar en Argentina (2003-2013). Espacio, Tiempo y Educación, v. 2, 2015.

; DOVAL, D. Libros aprobados - libros prohibidos. Libros recomendados. Argentina 1976-1982. En: ___ Una pedagogía de la renuncia.

El Perennialismo en Argentina (1976-1983). Paraná: Universidad Nacional de Entre Ríos, 1997.

LANZA, H.; FINOCCHIO, S. Curriculum presente, ciencia ausente. Buenos Aires: Miño y Dàvila, 1993. v. 3.

LEWKOWICZ, M; RODRIGUEZ, M. De los relatos nacionales a la comprensión de la complejidad social en los libros de texto. Actas de las XII Jornadas Interescuelas/Departamentos de Historia. Comahue, 2009

MARISTANY, J. Las ficciones del pasado en los manuales de historia argentina (1880-1910). En: KOHLER F. (ed.). Stéréotypes culturels et constructions identitaires. Tours: Presses Universitaires FrançoisRabelais; CIREMIA, 2007 (Série Études Hispaniques XVIII). et al. Argentina: los manuales que cuentan la historia (1860-1920). En: GUERAÑA, J.; OSSENBACH, G.; POZO, M. (dirs.). Manuales escolares en España, Portugal y América Latina (siglos XIX y XX). Madrid: UNED, 2005.

MUSCIA, A. Los manuales de moral e instrucción cívica en la escuela Argentina (1884-1916). En: OSSENBACH, G.; SOMOZA, M. Los manuales escolares como fuente para la Historia de la Educación en América Latina. Madrid: UNED, 2001.

PLOTKIN, M. Mañana es San Perón. Buenos Aires: Ariel, 1994.

RODRIGUEZ, L. La Historia que debía enseñarse durante la última dictadura militar en Argentina /1976-1983). Antíteses, v. 2, n. 3, 2009. 
; DOBAÑO, P. Los libros de texto como objeto de estudio. Buenos Aires: La Colmena, 2001.

. Libros de texto y sociedades: entre didáctica, política, cultura y mercado. Espacio, Tiempo y Educación, v. 2, 2015.

ROJAS, R. La restauración nacionalista. Buenos Aires: A. Peña Lillo, 1971.

ROMERO, L. A. (coord.). La Argentina en la escuela. La idea de nación en los textos escolares. Buenos Aires: Siglo XXI, 2004.

RÛSSEN, J. ¿Qué es la cultura histórica? Reflexiones sobre una nueva manera de abordar la historia. Disponible en: http://www.culturahistorica. es/ruesen/cultura_historica.pdf. Acceso el: 20 ago. 2015. Original en: FÜSSMANN, K.; GRÜTTER, H. T.; RÜSEN, J. (eds.). Historische Faszination. Geschichtskultur heute, 1994.

SIEDE, I. Preguntas y problemas en la enseñanza de las Ciencias Sociales. En: __ (coord.). Ciencias sociales en la escuela. Criterios y propuestas para la enseñanza. Buenos Aires: Aique, 2010.

VALLS, R. (dir.). Los procesos independentistas iberoamericanos en los manuales de Historia. Madrid: OEI- Fundación MAPFRE, 2005. 